\title{
Role of clay minerals in catalyzing orgamic matter transformation under oxic and anoxic conditions
}

\author{
QIANG ZENG ${ }^{1}$, HAILIANG DONG ${ }^{1,2}$, \\ ${ }^{1}$ Center for Geomicrobiology and Biogeochemistry Research, \\ State Key Laboratory of Biogeology and Environmental \\ Geology, China University of Geosciences, Beijing \\ 100083, China. zengqcugb@163.com \\ ${ }^{2}$ Department of Geology and Environmental Earth Science, \\ Miami University, OH 45056, USA. \\ dongh@miamioh.edu
}

The ubiquity of clay minerals in natural environments and their close interaction with organic matter (OM) affect terrestrial carbon cycling but it still remains incompletely understood. Here we explored both iron-rich and irondeficient smectite minerals in catalyzing $(\mathrm{OM})$ transformation under oxic and anoxic conditions.

Under oxic conditions, oxidation of structural $\mathrm{Fe}(\mathrm{II})$ in reduced nontronite produced hydroxyl radicals $(\cdot \mathrm{OH})$, a nonselective oxidant with a strong oxidizing ability. Addition of Fe-chelating agents such as phosphate, nitrilotriacetic acid (NTA) and ethylene diaminetetraacetic acid (EDTA) all significantly increased $\bullet \mathrm{OH}$ yield. NTA and EDTA increased the yield by switching the $\cdot \mathrm{OH}$ generation pathway from a heterogenous ones (i.e. on mineral surfaces) to homogenous ones (i.e. in solution phase). Phosphate increased the oxidant yield through changing the surface catalytic properties of nontronite through sorption. Humic acids (HA) also increased the $\cdot \mathrm{OH}$ yield from oxidation of reduced nontronite, with a similar mechanism to NTA and EDTA. More importantly, production of abundant $\cdot \mathrm{OH}$ significantly transformed HA molecules to compounds of smaller molecular size, bleached chromophores and altered chemical composition, leading to enhanced bio-availability of HA.

Under anoxic conditions, the effect of an Fe-poor smectite, montmorillonite, on OM transformation was evaluated by co-precipitating with ferrihydrite (Fh) and OM, which was subsequently bio-reduced byGeobacter sulfurreducens. G. sulfurreducens utilized mineral-bound $\mathrm{OM}$ as electron donor and/or carbon source to couple with Fh reduction. Addition of montmorillonite to Fh-OM complex enhanced the bio-reduction extent of Fh by increasing the proportion of bioavailable OM that was weakly bound to montmorillonite. Bio-reduction also transformed mineralbound $\mathrm{OM}$ to microbial products (e.g. necromass, extracellular polymeric substances), but $\mathrm{OM}$ with aromatic structures, carboxyl groups and large molecular weight were more resistant to microbial transformation. 